\title{
Bacterial profile and their antibiotic resistance patterns from blood culture in Intensive Care Unit patients at the University Of Gondar Comprehensive Specialized Hospital, Northwest Ethiopia.
}

Segen Tekle Gebreegziabher

Woldia University college of health science

Feleke Moges Yehuala

University of Gondar college of medicine and health sciences

Zemene Tigabu Kebede

University of Gondar college of medicine and health sciences

Alem Getaneh Mehari ( $\nabla$ alemgetaneh2@gmail.com )

University of Gondar College of Medicine and Health Sciences https://orcid.org/0000-0003-1608-6737

Research article

Keywords: Antibiotic resistance, ICU, ESBL, Gondar Ethiopia.

Posted Date: May 9th, 2019

DOI: https://doi.org/10.21203/rs.2.9515/v1

License: (c) (1) This work is licensed under a Creative Commons Attribution 4.0 International License. Read Full License 


\section{Abstract}

Abstract Background: The burden of bloodstream infection and antibiotic resistance in intensive care unit (ICU) is high when compared with other settings. The data on the changing antibiotic resistance trends are important for infection control activities. There is no sufficient data in the intensive care units of this hospital. Objective: The aims of this study were to assess the magnitude and risk factors of bacterial pathogens and their antibiotic resistance patterns of blood culture isolates from ICU patients at the University of Gondar Comprehensive Specialized Hospital, Gondar, Ethiopia. Materials and Methods: A cross-sectional study was conducted from February to May 2018.Blood specimen were collected from 384 patients and inoculated on appropriate culture media. Identification of bacterial pathogens and antibiotic susceptibility tests were performed using bacteriological standard methods. Presence of Extended Spectrum Beta Lactamase (ESBL) enzymes was confirmed by combined disk diffusion method. Data were analyzed using SPSS version 20. Result: Of the total 384 study participants, $96(25 \%)$ were culture positive. Majority of bacteria isolates $67(69.8 \%)$ were Gram negative. The commonly isolated bacterial species were K.pneumoniae 18(18.8\%), Coagulase negative Staphylococcus 13(13.5\%), K.ozanae 10(10.4\%), K.rhinose 8(8.3\%) and E.coli, E.cloacae, Citrobacter species, S.aureus each accounts 7(7.3\%). Gram negative isolates were found to be resistant to ampicillin $66(98 \%)$, amoxicillin/clavulanate 64(95\%) and ceftriaxone 52(77.6\%). However, amikacin 64(95.5\%), meropenem 58(87\%) and Ciprofloxacin 56(83.6\%) were relatively effective drugs. Gram positive isolates were found to be resistant to Penicillin 28(96.5\%), amoxicillin/clavulanate27 (93.1\%) and erythromycin 26(90\%). They were sensitive to ciprofloxacin 22(79\%) and clindamycin 24(83\%). Methicillin resistant S.aureus accounted 4(57.1\%) and ESBL enzyme producing Gram negative isolates accounted 41 (78.8\%). Conclusion: Klebsiella species were the predominant bacterial isolates in ICU settings. Antibiotic resistance due to ESBL enzyme production is alarmingly high. This result might be a reflection of inappropriate use of antibiotics and poor infection prevention control practice in these settings. Key words: Antibiotic resistance, ICU, ESBL, Gondar Ethiopia.

\section{Introduction}

Intensive care units (ICUs) are the most lifesaving units in a hospital in looking after critically ill patients by highly specialized clinicians and care giving nurses( 1). Most condition which are treated at ICU are life threatening, severe injuries and illnesses, which require constant follow up and support from specialized equipment's and medications in order to ensure normal body functions (2).

The rate of infections in the ICUs is rising, mainly because of increasing use of invasive procedures and specialized devices used(3).Some contribute to the wide spread of drug resistance among the hospital acquired organisms includes; antibiotic overuse and misuse partly due to incorrect diagnosis, irrational antibiotic market combinations; and irregular consumption due to either wrong prescription or poor compliance are among the reasons $(4,5)$.

Other risk factors, such as prolonged length of hospital stay, also seem to predispose patients to infection with antibiotic-resistant bacteria( 6). Occurrence of antibiotic-resistant bacterial infection due to inadequate infection control practices, failure to identify the presence of antibiotic resistance are also important factors promoting the spread of antibiotic resistance $(7,8)$.

Antibiotic resistance can be reduced by using antibiotics carefully based on guidelines of antimicrobial stewardship programs( 9).The most frequently reported pathogens in ICU settings are Staphylococcus aureus, enterobacteriaceae, Pseudomonas species. Enterococci species, Candida species, coagulase-negative staphylococci(CoNS) and Acinetobacter species( 10,11).

ICU-acquired infections have been associated with significant morbidity, mortality and rising healthcare costs in developing countries with limited resources $(12,13)$.Globally, patients in the ICU have encountered an increasing emergence and spread of antibiotic-resistant pathogens. The overall incidence rate is 23.7 infections per 1000 ICU admission days. Nosocomial infections in ICU account for about $20 \%$ to $25 \%$ of all nosocomial infection ( $13-15$ ).

Infection is a leading cause of death in the ICU as high as $60 \%$ and twice as much in those patients with a nosocomial infection ( 3 ). Intensive care units are one of the potential sources of nosocomial infections even in developed countries where extensive infection control measures are implemented( 15). But the prevalence of ICU-acquired infections is significantly higher in developing countries than in industrialized countries and the pooled cumulative incidence density is 17.0 episodes per 1000 patient-days in adult high-risk patients in developed countries. On the other hand, the incidence of ICU-acquired infection among adult patients in developing countries ranged from $4.4 \%$ up to $88.9 \%$ and pooled cumulative incidence density was 42.7 episodes per 1000 ICU days. Patients in ICU are a significant subgroup of all hospitalized patients accounting for about $20-25 \%$ of all hospital infections ( 16,17 ).

The mortality and morbidity rates of bloodstream infections (BSIs) in ICU are higher due to limited resources available associated with the quality of health care system in ICU. However, available data are lacking in developing countries like Ethiopia. Therefore, the overall aim of this study was to assess the magnitude of bacterial isolates, predominant associated risk factors and their resistance patterns from blood specimens in the ICU at the University of Gondar Comprehensive Specialized Hospital.

\section{Methods}

Study design, area and period

An institution based cross-sectional study was conducted at the University of Gondar Comprehensive Specialized Hospital from February to May 2018. The hospital is a teaching hospital which is located in Gondar town, $750 \mathrm{~km}$ far from Addis Ababa in the Northwest Ethiopia. In this town there are 8 health centers, 21 private clinics and one hospital in the town. The hospital provides surgical, medical, pediatric, gynecologic, obstetric, oncologic and ophthalmologic services to the community for over 5 million inhabitants. The hospital has only 4 beds for adult ICU (AICU) ,6 beds for pediatric ICU (PICU) and 36 beds for neonatal ICU (NICU) (18). 
Sample size and sampling technique

A total of 384 septicemia suspected ICU patients were enrolled by using convenient sampling technique. All patients who were admitted to AICU, PICU and NICU due to BSIs during the study period were included in the study.

Socio demographic data and sample collection

Socio demographic data such as age, sex, educational background, occupation, residence, patient setting, reason for ICU admission, antibiotic taken, and devices used during admission were collected using structured questioner. Two bottles of blood samples were collected by trained nurse working in the ICU under the supervision of the investigator by taking all aseptic techniques. Ten $\mathrm{ml}, 5 \mathrm{ml}$ and $1 \mathrm{ml}$ of blood sample was collected from adults, pediatrics and neonates respectively which were then inoculated in to tryptic soya broth. Blood samples were collected twice from different sites ( 19).

Laboratory processing

After inoculation the blood samples were incubated immediately at $35-37^{\circ} \mathrm{C}$ aerobically. After 18 hour of incubation, Gram stain was done and subcultured on to $5 \%$ sheep blood agar, MacConkey agar and Chocolate agar. MacConkey agar was incubated at $35-37^{\circ} \mathrm{Cfor} 18$ to $24 \mathrm{hours}$. Blood agar and Chocolate agar plates were incubated at $35-37^{\circ} \mathrm{C}$ in $5 \% \mathrm{CO}_{2}$ for 18 to 24 hours. If there is no growth on the Blood agar and chocolate agar; they were further incubated for 24 hours. Still if no growth Chocolate agar only was incubated for further 24 hours. The bottles were incubated for up to seven days under observation. If there is sign of growth sub cultured it: if not, sub cultured again at $3^{\text {rd }}$ and $6^{\text {th }}$ days of incubation.

Preliminary identification: Presumptive identification of bacteria was based on sign of growth on blood culture bottle, Gram reaction, and colony characteristics of the organisms like hemolysis on blood agar and changes in physical appearance in differential media..

Biochemical tests: were performed on isolated colonies for identification of bacterial pathogens based on their biochemical reactions. Catalase, coagulase, bacitracin and optochin tests were performed for Gram positive bacterial pathogens. For Gram negative bacteria isolates triple sugar iron agar, indole, citrate utilization, urease production, lysine decarboxylase and motility test were performed and interpreted.

Antibiotic susceptibility testing: Susceptibility testing was performed using the modified Kirby- Bauer disk diffusion method by using Muller Hinton Agar (Oxoid), chocolate agar (Oxoid), Muller Hinton agar with $5 \%$ sheep blood (Oxoid) agar based on the type of bacteria isolated. The suspension of the test organism was prepared by picking parts of similar test organisms with a sterile wire loop and suspend in test tube containing sterile physiological saline. The density of suspension was determined using $0.5 \mathrm{McF}$ arland standards. Then they were inoculated to agar by using sterile swab. The inoculums were allowed to dry for 5-15 minutes. Antibacterial discs were distributed $15 \mathrm{~mm}$ away from the edge and $\geq 24 \mathrm{~mm}$ apart from each other and incubated at $37^{\circ} \mathrm{C}$ for 24 hours. The results were expressed as susceptible, intermediate or resistant based on the 2017 CLSI guideline (20).

Antibiotic discs such as amoxycillin/ clavulanate(30 $\mu$ g), ciprofloxacin $(5 \mu \mathrm{g})$, gentamicin $(10 \mu \mathrm{g})$,trimethoprim/sulphamethaxzole $(25 \mu \mathrm{g})$, chloramphenicol

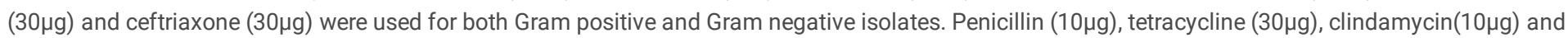
erythromycin $(15 \mu \mathrm{g})$ were used only for Gram positive isolates. Cefoxitin $(30 \mu \mathrm{g})$ were tested as a surrogate marker for oxacillin (methicillin). Ampicillin $(10 \mu \mathrm{g})$, cefotaxime $(30 \mu \mathrm{g})$, ceftazidime $(30 \mu \mathrm{g})$, amikacin $(30 \mu \mathrm{g})$ and meropenem( $(10 \mu \mathrm{g})$ were used only for Gram negative bacterial isolates.

Presence of ESBL for Enterobacteriaceae was suggested by screening resistance to a third generation cephalosporins such as cefotaxime (30 $\mu \mathrm{g}$ ), ceftriaxone $(30 \mu \mathrm{g})$ or ceftazidime $(30 \mu \mathrm{g})$ according to the CLSI screening criteria. The breakpoints indicative of suspicion for ESBL production was $\leq 22 \mathrm{~mm}$ for ceftazidime, $\leq 25 \mathrm{~mm}$ for ceftriaxone or $\leq 27 \mathrm{~mm}$ for cefotaxime. A combined disk method was used as a confirmatory phenotypic method for ESBL detection. ceftazidime $(30 \mu \mathrm{g})$ and cefotaxime $(30 \mu \mathrm{g})$ disks alone and their combinations with clavulanate $(30 \mu \mathrm{g} / 10 \mu \mathrm{g})$ were used for phenotypic confirmations of ESBL presence. $A \geq 5 \mathrm{~mm}$ increase in zone diameters for either of the cephalosporin disks or their respective cephalosporin/clavulanate disks was interpreted as ESBL producer (20).

Data analysis and interpretation

Data were entered, coded and cleaned using Epi-info version 7.0 statistical software and then transferred to SPSS software version 20 for further data processing and analysis. Text descriptions, tables, and figures were used to describe the relevant findings of the study. The crude odds ratios with a $95 \%$ confidence interval were estimated in the binary logistic regression analysis to assess the association between each independent variable and the outcome variable, and to select candidate variables for the multivariate logistic regression analysis. Thus, only those independent variables with a $p$ - values of 0.20 or less in the bivariate logistic regression were included in the multivariate logistic regression to get the adjusted effect of each covariate. Adjusted Odds Ratio with a $95 \%$ confidence interval was estimated to assess the strength of the association. P-value $\leq 0.05$ were considered as statistically significant.

\section{Results}

Socio-demographic characteristics of study participants

From the total of 384 septicemia suspected ICU patients 205 (53.4\%) of the study participants were males and 179 (46.6\%) were females. The age of the study participants ranged from 1 day-80 years with a median age of 21 days. Majority of the study participants were Neonates $207(53.9 \%)$ and rural dwellers, 267(69.5) (Table 1).

Clinical information of study participants 
Most common reasons for hospital admission included early onset neonatal sepsis 157 (40.9\%) followed by pyogenic meningitis 55(14.3\%) and late onset neonatal sepsis 38(9.9\%). Of the total admitted patients, 210(54.7\%) were admitted in NICU, 110(28.6\%) admitted in PICU and the rest 64(16.7\%) admitted in AICU. Of those patients $231(60.3 \%)$ were referred from other wards. In relation to antibiotic usage, $167(43.5 \%)$ had taken antibiotic before sample collection and $217(56.5 \%)$ didn't take any antibiotics. Most commonly prescribed drugs for those patients were ampicillin plus gentamicin $88(22.9 \%)$ and metronidazole plus ceftriaxone27 (7\%). Different mechanical devices were used for $172(44.8 \%)$ of the study participants (Table 2 ).

Etiologic Agents

Bacterial profile in ICU

Among 384 blood samples, 96 (25\%) organisms were isolated. Majority of bacterial isolates were Gram-negative, 67 (69.8\%) while the remaining 29(30.2\%) were Gram positive. The predominant isolates were K.pneumoniae 18(18.8\%) followed by CoNS13 (13.5\%), K.ozanae 10(10.4\%),K.rhinose 8(8.3\%), E.coli 7(7.3\%), E.cloacae7(7.3\%), Citrobacter species7(7.3) and S.aureus7(7.3\%) (Figure 1).

Figure 1:Percentage of bacterial isolates from blood culture of ICU patients at the University of Gondar Comprehensive Specialized Hospital from February to May 2018.

Majority of the bacterial isolates were found from neonates 65(67.7\%). The distribution bacterial isolates in NICU were K.pneumoniae10(15.4\%),CoNS8(12.3\%), K.ozanae 8(12.3\%), K.rihinose 7(10.7\%) and Citrobacter species 6(9.3\%). The rest of bacterial isolates were summarized in table 3 (Table3).

Antibiotic susceptibility test for Gram positive isolates

Most of the Gram positive bacterial isolates were found to be resistant to penicillin28 (96.5\%) followed by amoxicillin/clavulanate $27(93 \%)$, tetracycline $27(93 \%)$, trimethoprim-sulfamethoxazole 26(90\%), erythromycin 26(90\%),chloramphenicol 21(72\%),ceftriaxone19(65\%) and gentamicin 17(59\%). On the other hand, majority of the isolates were sensitive to clindamycin $24(83 \%)$ and ciprofloxacin 22(76\%). CoNS were13 (100\%) resistant to penicillin and amoxicillin/clavulanate followed by erythromycin 11(85\%), trimethoprim-sulfamethoxazole 11(85\%), tetracycline 11(85\%), Cefoxitin (61.5\%), chloramphenicol $8(61.5 \%)$ and ceftriaxone $7(54 \%)$. However $12(92.3 \%)$ and $8(61.5 \%)$ of these isolates were susceptible to clindamycin and ciprofloxacin respectively.

S. aureus, also demonstrated high level of resistance to penicillin 6(86\%), erythromycin $6(86 \%)$, trimethoprim-sulfamethoxazole 6 (86\%), tetracycline $6(86 \%)$, amoxicillin/clavulanate 5(71\%), chloramphenicol 4(57\%), and ceftriaxone 4(57\%). Whereas, ciprofloxacin 6(86\%), clindamycin 5(72\%) were sensitive against this isolate. Among those S. aureus strains 4(57.1\%) were MRSA. Other Gram positive isolates such as S.viridans and S.pneumoniae were 9(100\%) resistant to penicillin, gentamycin, erythromycin,chloramphenicol, trimethoprim-sulfamethoxazole and ceftriaxone (Table 4).

Antibiotic susceptibility test of Gram negative isolates

Majority of Gram negative isolates were highly resistant to ampicillin 66(98\%) followed by amoxicillin/clavulanate 64(95\%), trimethoprim-sulfamethoxazole $60(89 \%)$, chloramphenicol 52(77.6\%) and ceftriaxone 52(77.6\%), ceftazidime 45(67\%), cefuroxime, and gentamicin 44(66\%).However, amikacin 64(95.5\%), meropenem 58(87\%) and ciprofloxacin 56(83.6\%) were relatively effective against Gram- negative bacteria.

K. pneumoniae demonstrated high level of resistance to ampicillin 18(100\%), amoxicillin/clavulanate 17(94\%), ceftriaxone 17(94\%), chloramphenicol (83\%), trimethoprim-sulfamethoxazole 16(89\%) and gentamicin 9(50\%). On the other hand, amikacin 17(94\%), meropenem16 (89\%) and ciprofloxacin 13(72\%) were effective against this isolate.

E. coli was resistance to ampicillin 6(85.7\%), amoxicillin/clavulanate 5(71\%) and trimethoprim-sulfamethoxazole $4(57 \%)$ but susceptible for ciprofloxacin, amikacin and meropenem (Table 5).

Extended spectrum beta lactamase detection

Among the 67 Gram negative isolates of blood culture, 52 (77.6\%) were resistant to third generation cephalosporins (ceftriaxone, ceftazidime and cefotaxime). Based on the CLSI guideline, 43 isolates were checked for the confirmation of ESBL production by combined disk diffusion method. Providencia species, Serratia species, Citrobacter species and E.cloacae were excluded from ESBL testing.

The overall prevalence of confirmed ESBL producing Gram negative isolates were 39(90.6\%). Among these, K.ozenae and K.rhinose accounts18 (100\%) followed by K.pneumoniae 16(89\%). Among the 7 E. coli isolate, ESBL was found in 5(71.4\%) of the isolate. Among 39 ESBL producing isolates, $25(64 \%)$ were found from neonate's, $7(18 \%)$ from pediatrics and 7(18\%) from adults blood culture (Table 6).

Risk factors associated with bacterial bloodstream infections

The association between BSIs and suspected risk factors were assessed using logistic regression. The result of the logistic regression indicated that age $(A O R=2.65,95 \% \mathrm{Cl} ; 1.29-5.42, \mathrm{p}=0.008)$ and $\mathrm{Sex}(\mathrm{AOR}=2.0,95 \% \mathrm{Cl} ; 1.23-3.27, \mathrm{p}=0.005)$ were significantly associated with bacterial infection. Whereas

Page $4 / 12$ 
residence, place of admission, prior antibiotic therapy and device used were not significantly associated with bacterial infection in ICU settings. Those neonates were 2.65 times more likely to develop bacterial infection than adult age group. Patients who are male were 2 times more likely to develop bacterial infection than females (Table 7).

\section{Discussion}

In the current study, the overall prevalence of bacterial isolates was $25 \%$ which is similar with other studies conducted in India (23\% and $24.7 \%$ )( 21,22 ). However it is higher than another study in India (11.8\%), Pakistan (16\%), Jimma (15.8\%) and Gondar(18.2\%)( 23-26). This variation may be due to difference in target population, specimen's quality and bacteriological techniques.

Majority 67 (69.8\%) of bacteria isolates were Gram-negative while the remaining 29(30.2\%) were Gram positive isolates. The result is in line with a study done Kanpur, India reported that $60 \%$ Gram negative and $30 \%$ Gram positive organisms (21). However, our study is different from study reported from North India in which Gram negative to Gram positive rate was $39.3 \%$ and $53 \%$ respectively (22). This discrepancy may be due to the study participants were in the ICU admitted patients and quality of the specimen collection and processing methods.

According to the present study, the predominant and the commonest bacterial isolates was $K$. pneunoniae (18.8\%). This finding is similar with those studies conducted in India(19.7\% and 22\%) $(21,22)$ and higher than reported in Jimma (6.7\%) (26). This may be the study population in Jimma was adults but in the current study most participants were neonates.In this finding the percentage of E.coli was $7.3 \%$ which is similar with study done in Bangladesh (10.3\%) and Gondar $(7 \%)(23,27)$. However, our result is lower than research conducted in India which is $22 \%$ (21).

The result of the present study showed that among Gram positives isolates, CoNS (13.5\%) was the first in rank of isolation which is comparable with those reported in Kanpur, India (15\%), Jimma (13.3\%) and Indonesia $(14.9 \%)(15,21,26)$. These similarities may be due to CoNS are common saprophyte which causes disease among immunocompromised patients. S.aureus was second isolate which accounts $7.3 \%$. This result almost comparable with the study conducted in Bangladesh (5.3\%)( 27). However, it is lower than study conducted in Canada (21.1\%), India (33.5\%)( 28, 29).

Majority (67.7\%) of the bacterial isolates were identified from NICU which is in line with the finding in India (66.3\%) but higher than the study conducted in Gondar(46.6\%). The most prevalent isolate in this ICU was K.pneumoniae (15.4\%) similar to a previous study conducted in Gondar (28, 30). This may be due to the same study area after five years.

Among common isolates of Gram positive bacteria, S.aureus was found to be $7.3 \%$.Of these $57.1 \%$ was MRSA which was higher than other research conducted in Saudi Arabia(43\%) (31).Cefoxitin resistance CoNS has become the predominant pathogen. Cefoxitin resistance CoNS was also isolated in our findings (61.5\%).

In this investigation ciprofloxacin were relatively sensitive (78\%) to both Gram positive and Gram negative bacteria. In the current finding amikacin (95.5\%) was a drug of choice for gram negative bacteria similar to in North India(90.8\%)(32).

In the current findings, the overall prevalence of confirmed ESBL producing bacteria was 39(90.6\%). This result is higher than the finding in Mali (61.8\%), Addis Ababa (78.57\%) and Jimma (38.4\%) (33-35). The prevalence of ESBL production in E.coliand K.pneumonia was $71.4 \%$ and $89 \%$ respectively. The prevalence of ESBL producing K.pneumonia was higher from a report in Mali (71.4\%) and E. coli lower than a report in Ethiopia (100\%). Our study also was inconsistence with a report in Dhaka which was $81.8 \%$ of E.coli and 11.7\% of Klebsiella species had ESBL activity( $32-34$ ).

Furthermore, the logistic regression result indicated that independent risk factor for bacterial isolation in this finding was age (AOR=2.65, 95\% $\mathrm{Cl}$; $1.29-5.42$, $\mathrm{p}=0.008)$, which is consistence with result from United States and Sex ( $\mathrm{AOR}=2.0,95 \% \mathrm{Cl} ; 1.23-3.27, \mathrm{p}=0.005)$, similarly results shown in Italy (6.0\% vs. 8.9\%, $\mathrm{P}=0.001)$. Sex is significantly associated with severe sepsis in men than women $(36,37)$. This may be due to a combination of differences in chronic disease burden, environmental and social factors, and genetic disposition causing differences in the host immune response to infection likely contribute to the observed differences( 38$)$.

Limitations of the study

This study did not include other important pathogens responsible for sepsis such as anaerobic bacteria, fungus and viruses due to lack of laboratory facility. The study was also limited to conduct carbapenemase production among Gram negative isolates due to shortage of materials.

Conclusion

Gram-negative pathogens were the predominate isolates in bloodstream infections. Klebsiella species were the predominant bacterial isolates followed by CoNS identified in this study. The distribution of bacterial isolates was high in NICU followed by PICU and AICU. Ciprofloxacin and clindamycin were effective for Gram positive isolates. For Gram negative isolates, ciprofloxacin, amikacin and meropenem were effective. Extended spectrum beta lactamase production in gram negative isolates as well as methicillin resistant Staphylococcus species is alarmingly high. This leads to an increased patient hospital stay, cost and mortality. The current finding may be useful to formulate treatment guideline to avoid unnecessary use of broad spectrum antibiotics for the ICU patients and to promote researchers to conduct advanced studies on current challenges of antibiotic resistance. The data on the changing antibiotic resistance trends is also important for disease control activities in ICU settings.

\section{Abbreviations}


AICU: Adult Intensive Care Unit; BSI: Blood Stream Infection; CLSI: Clinical Laboratory Standards Institute; CoNS: Coagulase negative Staphylococcus; EONS: Early Onset Neonatal Sepsis; ESBL: Extended Spectrum Beta Lactamase; HAS: Hospital Acquired Sepsis; ICU: Intensive Care Unit; LONS: Late Onset Neonatal Sepsis; MRSA: Methicillin-resistant Staphylococcus aureus; NICU: Neonatal Intensive Care Unit; PICU: Paediatric Intensive Care Unit.

\section{Declarations}

Acknowledgements

The authors are pleased to acknowledge the study participants who accepted to participate in this study as well as Department of Medical Microbiology for their support by giving different materials and Medical Microbiology laboratory assistant for their technical support. Antibiotic disks for extended spectrum beta lactamase detection were also supported by the mega project of the University of Gondar in reference number of VP/RCS/05/192/2015.

Funding

Not applicable

Availability of data and materials

The datasets used and/or analyzed during the current study available from the corresponding author on reasonable request.

Authors' contributions

ST collected the data and wrote the manuscript. AG, FM and ZT gave valuable suggestions of the manuscript and revised the manuscript. All authors read and approved the final version of the manuscript.

Ethics approval and consent to participate

This study protocol was approved by the ethical review committee of the School of Biomedical and Laboratory Sciences, College of Medicine and Health Sciences, University of Gondar. The consent forms were taken from all study participants after explaining the objective of the study.

Consent for publication

Not applicable

Competing interests

The authors declare that they have no competing interests.

\section{References}

1. Banu SH. EEG in ICU: A monitoring tool for critically ill patient. Bangladesh Critical Care Journal. 2014;2(1):28-34.

2. Droogh JM, Smit M, Absalom AR, Ligtenberg JJ, Zijlstra JG. Transferring the critically ill patient: are we there yet? Critical Care. 2015;19(1):62.

3. Vincent J-L, Rello J, Marshall J, Silva E, Anzueto A, Martin CD, et al. International study of the prevalence and outcomes of infection in intensive care units. Jama. 2009;302(21):2323-9.

4. Javeri JR, Patel SM, Nayak SN, Desai K, Patel P. A study on bacteriological profile and drug sensitivity \& resistance pattern of isolates of the patients admitted in intensive care units of a tertiary care hospital in Ahmadabad. National Journal of Medical Research. 2012;2(3):330-4.

5. Zilahi G, Artigas A, Martin-Loeches I. What's new in multidrug-resistant pathogens in the ICU? Annals of intensive care. 2016;6(1):96.

6. Guggenbichler JP, Assadian O, Boeswald M, Kramer A. Incidence and clinical implication of nosocomial infections associated with implantable biomaterials-catheters, ventilator-associated pneumonia, urinary tract infections. GMS Krankenhaushygiene interdisziplinär. 2011;6(1).

7. Dancer SJ. Controlling hospital-acquired infection: focus on the role of the environment and new technologies for decontamination. Clinical microbiology reviews. 2014;27(4):665-90.

8. OhI CA, Luther VP. Antimicrobial stewardship for inpatient facilities. Journal of hospital medicine. 2011;6(S1).

9. Lee C-R, Cho IH, Jeong BC, Lee SH. Strategies to minimize antibiotic resistance. International journal of environmental research and public health. 2013;10(9):4274-305.

10. Gikas A, Roumbelaki M, Bagatzouni-Pieridou D, Alexandrou M, Zinieri V, Dimitriadis I, et al. Device-associated infections in the intensive care units of Cyprus: results of the first national incidence study. Infection. 2010;38(3):165-71. 
11. Malacarne P, Boccalatte D, Acquarolo A, Agostini F, Anghileri A, Giardino M, et al. Epidemiology of nosocomial infection in 125 Italian intensive care units. Minerva anestesiologica. 2010;76(1):13.

12. Sydnor ER, Perl TM. Hospital epidemiology and infection control in acute-care settings. Clinical microbiology reviews. 2011;24(1):141-73.

13. Mathai AS, Phillips A, Kaur P, Isaac R. Incidence and attributable costs of ventilator-associated pneumonia (VAP) in a tertiary-level intensive care unit (ICU) in northern India. Journal of infection and public health. 2015;8(2):127-35.

14. Laxminarayan R, Duse A, Wattal C, Zaidi AK, Wertheim HF, Sumpradit N, et al. Antibiotic resistance-the need for global solutions. The Lancet infectious diseases. 2013;13(12):1057-98.

15. Radji M, Fauziah S, Aribinuko N. Antibiotic sensitivity pattern of bacterial pathogens in the intensive care unit of Fatmawati Hospital, Indonesia. Asian Pacific journal of tropical biomedicine. 2011;1(1):39-42.

16. Allegranzi B, Nejad SB, Combescure C, Graafmans W, Attar H, Donaldson L, et al. Burden of endemic health-care-associated infection in developing countries: systematic review and meta-analysis. The Lancet. 2011;377(9761):228-41.

17. Abubakar AS, Barma MM, Balla HJ, Tanimu YS, Waru GB, Dibal J. Spectrum of bacterial isolates among intensive care unit patients in a tertiary hospital in northestern Nigeria. Ind J Sci Res and Tech. 2014;2(6):42-7.

18. Agency CS. Population projection of Ethiopia for all regions at wereda level from 2014-2017. Addis Ababa. 2013.

19. Cheesbrough M. District laboratory practice in tropical countries: Cambridge university press; 2006.

20. Patel JB. Performance standards for antimicrobial susceptibility testing: Clinical and Laboratory Standards Institute; 2017.

21. Pal N, Sujatha R. Antimicrobial Resistant Pattern of Blood Culture Isolates, Among Septicaemia Suspected Patients. National Journal of Laboratory Medicine. 2016;5(1):17-21.

22. Gill MK, Sharma S. Bacteriological profile and antibiotic resistance pattern in blood stream infection in critical care units of a tertiary care hospital in North India. Indian Journal of Microbiology Research. 2016;3(3):270-4.

23. Dagnew M, Yismaw G, Gizachew M, Gadisa A, Abebe T, Tadesse T, et al. Bacterial profile and antimicrobial susceptibility pattern in septicemia suspected patients attending Gondar University Hospital, Northwest Ethiopia. BMC research notes. 2013;6(1):283.

24. Fayyaz M, Mirza IA, Abbasi SA, Ikram A, Hussain A, Khan IU. Pattern of bacterial pathogens and their antimicrobial susceptibility from blood culture specimens in a tertiary care setting. J Virol Microbiol. 2015;1:1-7.

25. Mahesh C, Alex AM, Navaneeth B. Bacteriological profile and antibiotic susceptibility test of blood culture isolates in pediatric patients at a tertiary care teaching hospital. International Journal of Medical Microbiology and Tropical Diseases. 2017;3(1):31-6.

26. Kumalo A, Kassa T, Daka D, Tadesse AH. Bacterial Profile of Adult Sepsis and their Antimicrobial Susceptibility Pattern at Jimma University Specialized Hospital, South West Ethiopia. Health Science Journal. 2016;10(2).

27. Akter T, Murshed M, Begum T, Nahar K, Duza SS, Shahnaz S. Antimicrobial Resistance Pattern of Bacterial Isolates from Intensive Care Unit of a Tertiary Care Hospital in Bangladesh. Bangladesh Journal of Medical Microbiology. 2017;8(1):7-11.

28. Sangwan J, Mane P, Vohra P, Lathwal S, Malik A. Bacteriologic Profile and Antimicrobial Resistance of Blood Culture Isolates of Septicemic Patients from Various Intensive Care Units in a Teaching Tertiary Care Institute of Haryana, India. Int J Curr Microbiol App Sci. 2016;5(7):599-608.

29. Zhanel GG, DeCorby M, Laing N, Weshnoweski B, Vashisht R, Tailor F, et al. Antimicrobial-resistant pathogens in intensive care units in Canada: results of the Canadian National Intensive Care Unit (CAN-ICU) study, 2005-2006. Antimicrobial Agents and Chemotherapy. 2008;52(4):1430-7.

30. Moges F, Eshetie S, Yeshitela B, Abate E. Bacterial etiologic agents causing neonatal sepsis and associated risk factors in Gondar, Northwest Ethiopia. BMC pediatrics. 2017;17(1):137.

31. Al-Ahmadey ZZ, Mohamed SA. Antimicrobial susceptibility pattern of bacterial isolates in the intensive care unit of Al-Ansar Hospital, Saudi Arabia. Eur J Adv Res Bio Life Science. 2013;1:17-26.

32. Gupta S, Kashyap B. Bacteriological profile and antibiogram of blood culture isolates from a tertiary care hospital of North India. Tropical Journal of Medical Research. 2016;19(2):94.

33. Sangare SA, Maiga Al, Guindo I, Maiga A, Camara N, Dicko OA, et al. Prevalence of ESBL-producing Enterobacteriaceae isolated from blood cultures in Mali. The Journal of Infection in Developing Countries. 2016;10(10):1059-64.

34. Legese MH, Weldearegay GM, Asrat D. Extended-spectrum beta-lactamase-and carbapenemase-producing Enterobacteriaceae among Ethiopian children. Infection and drug resistance. 2017;10:27. 
35. Siraj SM, Ali S, Wondafrash B. Extended-spectrum $\beta$-lactamase production in Klebsiella pneumoniae and Escherichia coli at Jimma University

Specialized Hospital, South-West, Ethiopia. Molecular Microbiology Research. 2015;5.

36. Watson RS, Carcillo JA, Linde-Zwirble WT, Clermont G, Lidicker J, Angus DC. The epidemiology of severe sepsis in children in the United States. American journal of respiratory and critical care medicine. 2003;167(5):695-701.

37. Sakr Y, Elia C, Mascia L, Barberis B, Cardellino S, Livigni S, et al. The influence of gender on the epidemiology of and outcome from severe sepsis. Critical Care. 2013;17(2):R50.

38. Mayr FB, Yende S, Angus DC. Epidemiology of severe sepsis. Virulence. 2014;5(1):4-11.

\section{Tables}

Table 1: Socio-demographic characteristics of ICU patients at the University of Gondar Comprehensive Specialized Hospital from February to May 2018.

\begin{tabular}{lll}
\hline Characteristics & & Number (\%) \\
\hline Age & Neonate (0-28days) & $207(53.9)$ \\
& Pediatrics (29day-18 year) & $113(29.4)$ \\
Sex & Adult (>18 Years) & $64(16.7)$ \\
Residence & Male & $205(53.4)$ \\
& Female & $179(46.6)$ \\
Occupation & Rural & $267(69.5)$ \\
& Urban & $117(30.5)$ \\
& Farmer & $19(4.9)$ \\
& Civil servants & $6(1.6)$ \\
& Self-employee & $20(5.2)$ \\
& Daily laborer & $4(1)$ \\
& House wife & $17(4.4)$ \\
& Merchant & $2(0.5)$ \\
& Others** & $2(0.5)$ \\
& N/A & $314(81.8)$ \\
Educational status & Illiterate & $17(4.4)$ \\
& Primary & $58(15.1)$ \\
& Secondary & $28(7.3)$ \\
& College and above & $6(1.6)$ \\
& N/A* & $275(71.6)$ \\
\hline
\end{tabular}

N/A* $=$ Patients who are $<6$-years-old, others** $=$ Carpenter, Beiger.

Table 2: Clinical information of ICU patients at the University of Gondar Comprehensive Specialized Hospital from February to May 2018. 


\begin{tabular}{lll}
\hline Independent Variables & & Number (\%) \\
\hline \multirow{4}{*}{ Clinical diagnosis } & EONS & $157(40.9)$ \\
& LONS & $38(9.9)$ \\
& Pyogenic meningitis & $55(14.3)$ \\
& LAS & $29(7.6)$ \\
& Pneumonia & $26(6.8)$ \\
& Complicated UTI & $37(9.6)$ \\
& Infective endocarditis & $21(2.9)$ \\
& Others* & $10(2.6)$ \\
Place of admission & NICU & $210(54.7)$ \\
& PICU & $110(28.6)$ \\
& AICU & $64(16.7)$ \\
Admitted from & Other wards & $231(60.2)$ \\
& Health center & $59(15.4)$ \\
& Other hospital & $23(6))$ \\
Prior antibiotic therapy & Home & $71(18.5$ \\
Mechanical device used & Yes & $167(43.5)$ \\
& No & $217(56.5)$ \\
& No & $172(44.8)$ \\
& & $212(55.2)$ \\
\hline
\end{tabular}

Keys: Others*- multiple trauma, hemorrhagic shock and acute kidney injury. EONS-Early Onset Neonatal Sepsis, LONS-Late Onset Neonatal Sepsis, HAS- Hospital Acquired Sepsis, UTI-Urinary Tract Infection,NICU-Neonatal Intensive Care Unit, PICU- Paediatric Intensive Care Unit, AICU-Adult Intensive Care Unit.

Table 3: Distribution of bacterial isolates of blood culture in different ICU patients at the University of Gondar Comprehensive Specialized Hospital from February to May 2018.

\begin{tabular}{lllll}
\hline Type of organism isolated & NICU N (\%) & PICU N (\%) & AICU N (\%) & Total N(\%) \\
\hline K.pneumoniae & $10(15.4)$ & $6(30)$ & $2(18.3)$ & $18(18.75)$ \\
CoNS & $8(12.3)$ & $4(20)$ & $1(9.0)$ & $13(13.54)$ \\
\hline K.ozenae & $8(12.3)$ & 0 & $2(18.3)$ & $10(10.41)$ \\
\hline K.rhinose & $7(10.7)$ & $1(5.0)$ & 0 & $8(8.33)$ \\
\hline E.coli & $3(4.6)$ & $1(5.0)$ & $3(27.4)$ & $7(7.29)$ \\
\hline Citrobacter species & $6(9.3)$ & 0 & $1(9.0)$ & $7(7.29)$ \\
\hline E.cloacae & $7(10.7)$ & 0 & 0 & $7(7.29)$ \\
\hline S.aureus & $4(6.2)$ & $3(15)$ & 0 & $7(7.29)$ \\
\hline S.viridans & $4(6.2)$ & $1(5.0)$ & $1(9.0)$ & $6(6.25)$ \\
\hline Providencia species & $3(4.6)$ & $1(5.0)$ & $1(9.0)$ & $5(5.2)$ \\
\hline Serratia species & $4(6.2)$ & 0 & 0 & $4(4.17)$ \\
\hline S.pneumonae & $1(1.5)$ & $2(10)$ & 0 & $3(3.12)$ \\
\hline Neisseria species & 0 & $1(5.0)$ & 0 & $1(1)$ \\
\hline Total & $65(67.7)$ & $20(20.8)$ & $11(11.5)$ & 96 \\
\hline
\end{tabular}

Keys: NICU-Neonatal Intensive Care Unit, PICU- Paediatric Intensive Care Unit, AICU-Adult Intensive Care Unit.

Table 4: Antibiotic susceptibility patterns of Gram positive bacterial isolates from blood culture of ICU patients at the University of Gondar Comprehensive Specialized Hospital from February to May 2018. 


\begin{tabular}{|c|c|c|c|c|c|c|c|c|c|c|c|c|}
\hline $\begin{array}{l}\text { Bacterial } \\
\text { isolate }\end{array}$ & Patterns & $\begin{array}{l}\text { PG } \\
\text { N (\%) }\end{array}$ & $\begin{array}{l}\text { Amox/clav } \\
\text { N (\%) }\end{array}$ & \begin{tabular}{|l} 
CIP \\
N (\%)
\end{tabular} & \begin{tabular}{|l|} 
FOX \\
N (\%) \\
\end{tabular} & \begin{tabular}{|l|} 
GN \\
N (\%) \\
\end{tabular} & \begin{tabular}{|l|} 
ERY \\
N (\%) \\
\end{tabular} & \begin{tabular}{|l|} 
CAF \\
N (\%) \\
\end{tabular} & \begin{tabular}{|l|} 
SXT \\
N (\%) \\
\end{tabular} & $\begin{array}{l}\text { CRO } \\
\mathrm{N}(\%) \\
\end{array}$ & \begin{tabular}{|l|} 
DA \\
N (\%)
\end{tabular} & $\begin{array}{c}\mathrm{TE} \\
\mathrm{N}(\%)\end{array}$ \\
\hline \multicolumn{13}{|l|}{ Gram positive } \\
\hline \multirow[t]{3}{*}{ CoNS } & S & $0(0)$ & $0(0)$ & $\begin{array}{l}8 \\
(61.5)\end{array}$ & $\begin{array}{l}5 \\
(38.5)\end{array}$ & $\begin{array}{l}6 \\
(46.2)\end{array}$ & $2(15.4)$ & $\begin{array}{l}5 \\
(38.5)\end{array}$ & $2(15.4)$ & $\begin{array}{l}5 \\
(38.5)\end{array}$ & $12(92.3)$ & $2(15.4)$ \\
\hline & I & $0(0)$ & $0(0)$ & $1(7.7)$ & $0(0)$ & $\begin{array}{l}1 \\
(7.7)\end{array}$ & $0(0)$ & $0(0)$ & $0(0)$ & $\begin{array}{l}1 \\
(7.7)\end{array}$ & $0(0)$ & $0(0)$ \\
\hline & $\mathrm{R}$ & $13(100)$ & 13(100) & $\begin{array}{l}4 \\
(30.8)\end{array}$ & $\begin{array}{l}8 \\
(61.5)\end{array}$ & $\begin{array}{l}6 \\
(46.2)\end{array}$ & $11(84.6)$ & $\begin{array}{l}8 \\
(61.5)\end{array}$ & $11(84.6)$ & $\begin{array}{l}7 \\
(53.8)\end{array}$ & $1(7.7)$ & $11(84.6)$ \\
\hline \multirow[t]{3}{*}{ S.aureus } & S & $1(14.3)$ & $2(28.6)$ & $\begin{array}{l}6 \\
(85.7)\end{array}$ & $3(42.9)$ & $\begin{array}{l}4 \\
(57.1)\end{array}$ & 1 (14.3) & $3(42.9)$ & $1(14.3$ & $\begin{array}{l}3 \\
(42.9)\end{array}$ & $5(71.4)$ & $0(0)$ \\
\hline & I & $0(0)$ & $0(0)$ & $0(0)$ & $0(0)$ & $0(0)$ & $0(0)$ & $0(0)$ & $0(0)$ & $0(0)$ & $0(0)$ & $0(0)$ \\
\hline & $\mathrm{R}$ & $6(85.7)$ & $5(71.4)$ & $\begin{array}{l}1 \\
(14.3)\end{array}$ & $\begin{array}{l}4 \\
(57.1)\end{array}$ & $\begin{array}{l}3 \\
(42.9)\end{array}$ & 6 (85.7) & $\begin{array}{l}4 \\
(57.1)\end{array}$ & 6 (85.7) & $\begin{array}{l}4 \\
(57.1)\end{array}$ & 2 (28.6) & $7(100)$ \\
\hline \multirow[t]{3}{*}{ S.viridans } & $\mathrm{S}$ & $0(0)$ & $0(0)$ & $6(100)$ & $0(0)$ & $0(0)$ & $0(0)$ & $0(0)$ & $0(0)$ & $0(0)$ & 5 (83.3) & $0(0)$ \\
\hline & I & $0(0)$ & $0(0)$ & $0(0)$ & $0(0)$ & $0(0)$ & $0(0)$ & $0(0)$ & $0(0)$ & $0(0)$ & $0(0)$ & $0(0)$ \\
\hline & $\mathrm{R}$ & $6(100)$ & $6(100)$ & $0(0)$ & $6(100)$ & $\begin{array}{l}6 \\
(100)\end{array}$ & $6(100)$ & $6(100)$ & $6(100)$ & $\begin{array}{l}6 \\
(100)\end{array}$ & 1 (16.7) & $6(100)$ \\
\hline \multirow[t]{3}{*}{ S.pneumoniae } & S & $0(0)$ & $0(0)$ & $\begin{array}{l}2 \\
(66.7)\end{array}$ & $\begin{array}{l}1 \\
(33.3)\end{array}$ & \begin{tabular}{|l}
1 \\
$(33.3)$
\end{tabular} & $0(0)$ & $0(0)$ & $0(0)$ & $\begin{array}{l}1 \\
(33.3)\end{array}$ & 2 (66.7) & $0(0)$ \\
\hline & I & $0(0)$ & $0(0)$ & $0(0)$ & $0(0)$ & $0(0)$ & $0(0)$ & $0(0)$ & $0(0)$ & $0(0)$ & $0(0)$ & $0(0)$ \\
\hline & $\mathrm{R}$ & $3(100)$ & $3(100)$ & $\begin{array}{l}1 \\
(33.3)\end{array}$ & $\begin{array}{l}2 \\
(66.7)\end{array}$ & $\begin{array}{l}2 \\
(66.7)\end{array}$ & $3(100)$ & $3(0)$ & $3(100)$ & $\begin{array}{l}2 \\
(66.7)\end{array}$ & $1(33.3)$ & $3(100)$ \\
\hline
\end{tabular}

Keys: S-Sensitive, I- Intermediate, R- Resistance. PG-Penicillin G, Amox/clav- Amoxicillin/clavulanate, CIP- Ciprofloxacin, FOX-Cefoxitin, GN-Gentamicin, ERY-Erythromycin, CAF-Chloramphenicol, SXT-Trimethoprim-sulfamethoxazole, CRO- Ceftriaxone, DA- Clindamycin, TE- Tetracycline.

Table 5: Antibiotic susceptibility patterns of Gram negative bacterial isolates from blood culture of ICU patients at the University of Gondar Comprehensive Specialized Hospital from February to May 2018.

\begin{tabular}{|c|c|c|c|c|c|c|c|c|c|c|c|c|}
\hline Bacterial isolate & Pattern & $\begin{array}{l}\text { AMP } \\
\text { N (\%) }\end{array}$ & $\begin{array}{l}\text { Amox/clav } \\
\mathrm{N}(\%)\end{array}$ & $\begin{array}{l}\text { CIP } \\
\text { N(\%) }\end{array}$ & \begin{tabular}{|l|} 
GN \\
N(\%) \\
\end{tabular} & $\begin{array}{l}\text { CAF } \\
\text { N(\%) }\end{array}$ & $\begin{array}{l}\text { SXT } \\
\mathrm{N}(\%)\end{array}$ & $\begin{array}{l}\text { CRO } \\
\text { N(\%) }\end{array}$ & $\begin{array}{l}\mathrm{CAZ} \\
\mathrm{N}(\%) \\
\end{array}$ & $\begin{array}{l}\text { CAX } \\
\text { N(\%) } \\
\end{array}$ & $\begin{array}{l}\text { AMK } \\
\text { N(\%) }\end{array}$ & $\begin{array}{l}\text { MER } \\
\text { N(\%) }\end{array}$ \\
\hline \multicolumn{13}{|l|}{ Gram Negative } \\
\hline \multirow[t]{3}{*}{ K.pneumoniae } & $\mathrm{S}$ & $0(0)$ & $0(0)$ & $13(72.2)$ & $8(44.4)$ & $3(16.7$ & $2(11)$ & $1(5.5))$ & $1(5.5)$ & $6(33)$ & $17(94)$ & $16(88.9)$ \\
\hline & I & $0(0)$ & $1(5.6)$ & $2(11.1)$ & $1(5.60)$ & $0(0)$ & $0(0)$ & $0(0)$ & $1(5.5)$ & $0(0)$ & $1(6)$ & $0(0)$ \\
\hline & $\mathrm{R}$ & $18(100)$ & $17(94.4)$ & $3(16.7)$ & $9(50)$ & $15(83.3$ & $16(89$ & 17(94.5)) & $16(89)$ & $12(67)$ & $0(0)$ & $2(11.1)$ \\
\hline \multirow[t]{3}{*}{ K.ozanae } & $\mathrm{S}$ & $0(0)$ & $0(0)$ & $10(100)$ & $3(30)$ & $2(20)$ & $0(0)$ & $2(20)$ & $0(0)$ & $3(30)$ & $10(100$ & $8(80)$ \\
\hline & I & $0(0)$ & $0(0)$ & $0(0)$ & $0(0)$ & $0(0)$ & $0(0)$ & $0(0)$ & $0(0)$ & $0(0)$ & $0(0)$ & $1(10)$ \\
\hline & $\mathrm{R}$ & $10(100)$ & $10(100)$ & $0(0)$ & $7(70)$ & $8(80)$ & $10(100$ & $8(80)$ & $10(100)$ & $7(70)$ & $0(0)$ & $1(10)$ \\
\hline \multirow{3}{*}{ K.rhinose } & $\mathrm{S}$ & $0(0)$ & $0(0)$ & $8(100)$ & $2(25)$ & $1(12.5)$ & $0(0)$ & $0(0)$ & $3(37.5)$ & $2(25)$ & $8(100)$ & $6(75)$ \\
\hline & I & $0(0)$ & $0(0)$ & $0(0)$ & $0(0)$ & $2(25)$ & $0(0)$ & $0(0)$ & $0(0)$ & $0(0)$ & $0(0)$ & $0(0)$ \\
\hline & $\mathrm{R}$ & $8(100)$ & $8(100)$ & $0(0)$ & $6(75)$ & $5(62.5)$ & $7(100$ & $8(100)$ & $5(62.5)$ & $6(75)$ & $0(0)$ & $2(25)$ \\
\hline \multirow[t]{3}{*}{ E.coli } & S & $0(0)$ & $2(28.6)$ & $7(100)$ & $6(85.7)$ & $1(14.3)$ & $0(0)$ & $1(14.3$ & $0(0)$ & $0(0)$ & $7(100)$ & $7(100)$ \\
\hline & I & $1(14.3)$ & $0(0)$ & $0(0)$ & $0(0)$ & $0(0)$ & $0(0)$ & $0(0)$ & $0(0)$ & $0(0)$ & $0(0)$ & $0(0)$ \\
\hline & $\mathrm{R}$ & $6(85.7)$ & $5(71.4)$ & $0(0)$ & $1(14.3)$ & $6(85.7)$ & $7(100)$ & $6(85.7$ & $7(100)$ & $7(100)$ & $0(0)$ & $0(0)$ \\
\hline \multirow[t]{3}{*}{ E.cloacae } & S & $0(0)$ & $0(0)$ & $7(100)$ & $2(28.6)$ & $1(14.3)$ & $1(14)$ & $7(00)$ & $7(100)$ & $7(100)$ & $7(100)$ & $7(100)$ \\
\hline & I & $0(0)$ & $0(0)$ & $0(0)$ & $0(0)$ & $0(0)$ & $0(0)$ & $0(0)$ & $0(0)$ & $0(0)$ & $0(0)$ & $0(0)$ \\
\hline & $\mathrm{R}$ & $7(100)$ & $7(100)$ & $0(0)$ & $5(71.4)$ & $6(85.6)$ & $6(86)$ & $0(0)$ & $0(0)$ & $0(0)$ & $0(0)$ & $0(0)$ \\
\hline \multirow[t]{3}{*}{ Citrobacter species } & S & $0(0)$ & $0(0)$ & $5(71.4)$ & $0(0)$ & $0(0)$ & $0(0)$ & $2(28.6)$ & $2(28.6)$ & $1(14.3)$ & $6(85.7)$ & $6(85.7))$ \\
\hline & I & $0(0)$ & $0(0)$ & $0(0)$ & $0(0)$ & $0(0)$ & $0(0)$ & $0(0)$ & $0(0)$ & $0(0)$ & $0(0)$ & $0(0)$ \\
\hline & $\mathrm{R}$ & $7(100)$ & $7(100)$ & $2(28.6)$ & $7(100)$ & $7(100)$ & $7(100$ & $5(71.4)$ & $5(71.4)$ & $6(85.7)$ & $1(14.3)$ & $1(14.3)$ \\
\hline \multirow[t]{3}{*}{ Providencia species } & S & $0(0)$ & $0(0)$ & $3(60)$ & $0(0)$ & $0(0)$ & $0(0)$ & $2(40)$ & $1(20)$ & $1(20)$ & $4(80)$ & $3(60)$ \\
\hline & I & $0(0)$ & $0(0)$ & $0(0)$ & $0(0)$ & $0(0)$ & $0(0)$ & $0(0)$ & $0(0)$ & $0(0)$ & $0(0)$ & $0(0)$ \\
\hline & $\mathrm{R}$ & $5(100)$ & $5(100)$ & $2(40)$ & $5(100)$ & $5(100)$ & $5(100$ & $3(60)$ & $4(80)$ & $4(80)$ & $1(20)$ & $2(40)$ \\
\hline \multirow[t]{3}{*}{ Serratia } & S & $0(0)$ & $0(0)$ & $2(50)$ & $0(0)$ & $0(0)$ & $0(0)$ & $1(25)$ & $0(0)$ & $0(0)$ & $4(100)$ & $3(75)$ \\
\hline & I & $0(0)$ & $0(0)$ & $0(0)$ & $0(0)$ & $0(0)$ & $0(0)$ & $0(0)$ & $0(0)$ & $0(0)$ & $0(0)$ & $0(0)$ \\
\hline & $\mathrm{R}$ & $4(100)$ & $4(100)$ & $2(50)$ & $4(100)$ & $4(100)$ & $4(100$ & $3(75)$ & $4(100)$ & $4(100)$ & $0(0)$ & $1(25)$ \\
\hline \multirow[t]{3}{*}{ Neisseria species } & $\mathrm{S}$ & $0(0)$ & $0(0)$ & $1(100)$ & $1(100)$ & $0(0)$ & $0(0)$ & $0(0)$ & $1(100)$ & $0(0)$ & $1(100)$ & $1(100)$ \\
\hline & I & $0(0)$ & $0(0)$ & $0(0)$ & $0(0)$ & $0(0)$ & $0(0)$ & $0(0)$ & $0(0)$ & $0(0)$ & $0(0)$ & $0(0)$ \\
\hline & $\mathrm{R}$ & $1(100)$ & $1(100)$ & $0(0)$ & $0(0)$ & $1(100)$ & $1(100$ & $1(100)$ & $0(0)$ & $1(100)$ & $0(0)$ & $0(0)$ \\
\hline
\end{tabular}

Keys: S-Sensitive, I- Intermediate R- Resistance, AMP-Ampicillin, Amox/clav- Amoxicillin/clavulanate, CIP- Ciprofloxacillin GN-Gentamicin CAF-Chloramphenicol, SXTTrimethoprim-sulfamethoxazole, CRO- Ceftriaxone, CAZ-Ceftazidime, CAX- Cefuroxime, AMK-Amikacin, MER- Meropenem 
Table 6: Extended spectrum beta lactamase production confirmed by combined disk diffusion method in Gram negative isolates from blood culture of ICU patients at the University of Gondar Comprehensive Specialized Hospital from February to May 2018.

\begin{tabular}{lll}
\hline Organisms & ESBL* positive & ESBL* negative \\
\hline K.pneumoniae(18) & $16(89 \%)$ & $2(11 \%)$ \\
K.ozenae(10) & $10(100 \%)$ & 0 \\
K.rhinose(8) & $8(100 \%)$ & 0 \\
E.coli $(7)$ & $5(71.4 \%)$ & $2(28.6 \%)$ \\
Total $(43)$ & $39(90.6)$ & $4(9.4)$ \\
\hline
\end{tabular}

ESBL*-Extended spectrum beta lactamase.

Table 7. Risk factors associated with bacterial infection from blood culture of ICU admitted patients at the University of Gondar Comprehensive Specialized Hospital from February to May 2018.

\begin{tabular}{|c|c|c|c|c|c|c|c|}
\hline \multicolumn{2}{|l|}{ Variables } & \multicolumn{2}{|c|}{ Organisms isolated } & \multicolumn{2}{|c|}{ Bivariate analysis } & \multicolumn{2}{|c|}{ Multivariable analysis } \\
\hline & & Yes & No & COR (95\% CI) & p-value & AOR (95\% CI) & P-value \\
\hline \multirow[t]{3}{*}{ Age } & Neonates & 65 & 142 & $2.47(1.22-5.00)$ & 0.012 & $2.65(1.29-5.42)$ & 0.008 \\
\hline & pediatrics & 20 & 93 & $1.13(0.5-2.54)$ & 0.775 & $1.1(0.5-2.5)$ & 0.75 \\
\hline & Adult & 11 & 53 & 1 & & 1 & \\
\hline \multirow[t]{2}{*}{ Sex } & Male & 62 & 143 & $1.84(1.1-2.9)$ & 0.012 & $2.0(1.23-3.27)$ & 0.005 \\
\hline & Female & 34 & 145 & 1 & & 1 & \\
\hline \multirow[t]{2}{*}{ Residence } & Rural & 73 & 194 & $1.54(0.9-2.6)$ & 0.11 & & 0.12 \\
\hline & Urban & 23 & 94 & 1 & & & \\
\hline \multirow[t]{3}{*}{ Place of admission } & NICU & 65 & 145 & $2.48(1.2-5.0)$ & 0.011 & & 0.2 \\
\hline & PICU & 20 & 82 & $1.35(0.6-3.0)$ & 0.46 & & 0.1 \\
\hline & AICU & 11 & 61 & 1 & & & \\
\hline \multirow[t]{2}{*}{ Admitted to ICU from } & Medical center & 85 & 228 & $2.03(1.0-4.0)$ & 0.04 & & 0.1 \\
\hline & Home & 11 & 60 & 1 & & & 0.29 \\
\hline \multirow[t]{2}{*}{ Prior antibiotic therapy } & Yes & 48 & 119 & $1.42(0.8-2.2)$ & 0.13 & & 0.19 \\
\hline & No & 48 & 169 & 1 & & & \\
\hline \multirow[t]{2}{*}{ Device used } & Yes & 46 & 126 & $1.18(0.7-1.8$ & 0.4 & & 0.7 \\
\hline & No & 50 & 162 & 1 & & & \\
\hline
\end{tabular}

Keys: COR- Crude odds ratio, AOR-Adjusted odds ratio, NICU-neonatal intensive care unit, PICU- paediatric Intensive Care Unit, AICUadult intensive care unit.

\section{Figures}




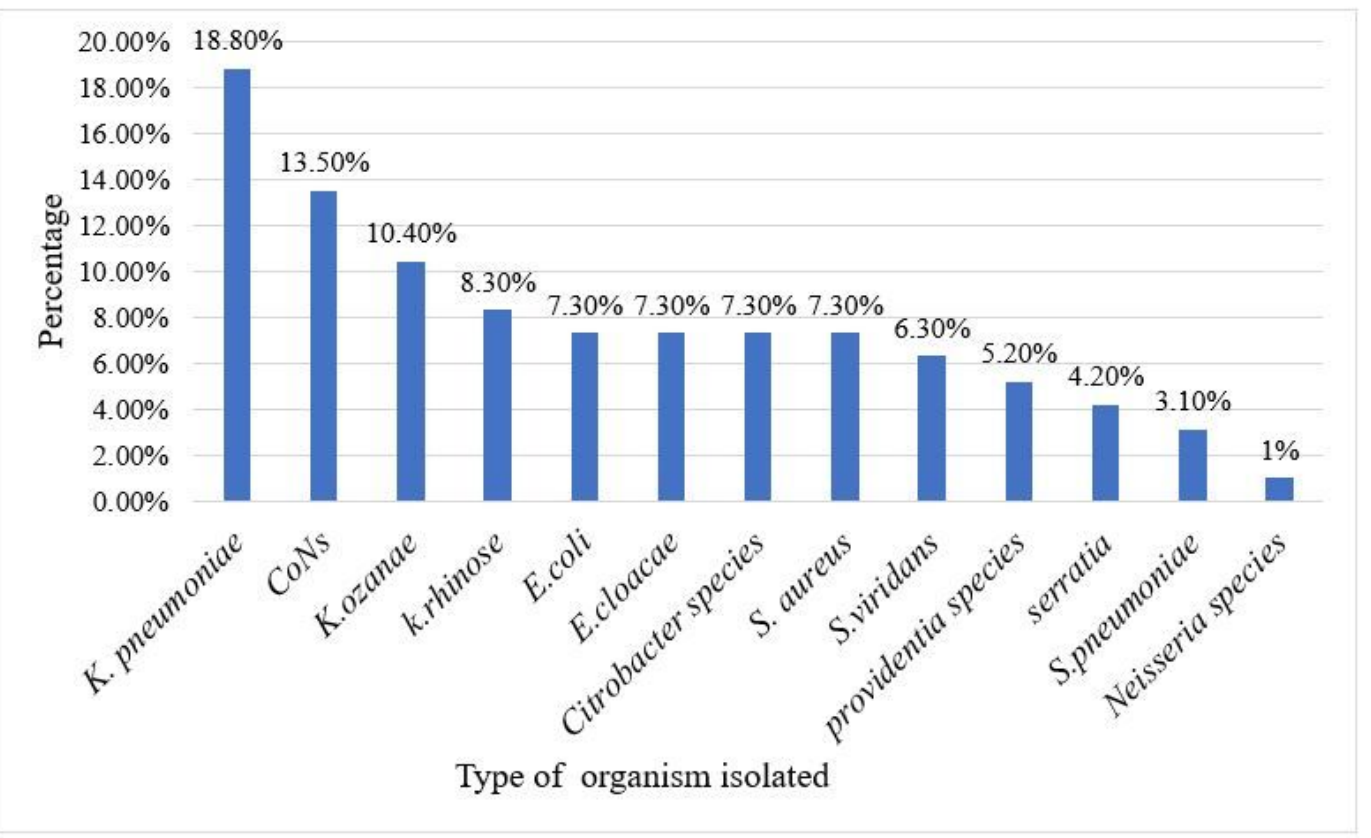

Figure 1

Percentage of bacterial isolates from blood culture of ICU patients at the University of Gondar Comprehensive Specialized Hospital from February to May 2018. 